\title{
Utilization of Punica granatum peel as an eco-friendly biosorbent for the removal of methylene blue dye from aqueous solution
}

\begin{abstract}
Punica granatum peels (PGP) have successfully been employed as a natural nonconventional low-cost adsorbent for the removal of methylene blue (MB) dye from aqueous solution. Fourier Transform Infra-Red analysis was performed to identify the functional groups present in PGP. Surface morphology of PGP before and after adsorption with MB was studied by analyzing micrograph images of Scanning Electron Microscopy (SEM). The equilibrium and kinetic data were analyzed in the light of different available isotherm and kinetic models. It has been observed that the MB removal by PGP obeys the Temkin adsorption model and pseudo-second-order kinetics. The study has also been extended for the desorption studies of MB from PGP adsorbent. The diluted $\mathrm{HCl}$ has been observed to be a most efficient desorbing agent.
\end{abstract}

Keywords: punica granatum peels, adsorption, isotherm modeling, kinetics, methylene blue, thermodynamics, desorption, DDDW
Volume 5 Issue 4 - 2018

\author{
Sadia Shakoor,Abu Nasar \\ Department of Applied Chemistry, Aligarh Muslim University, \\ India
}

Correspondence: Abu Nasar, Department of Applied Chemistry, Faculty of Engineering and Technology, Aligarh Muslim University,Aligarh-202 002, India, Fax +91 057| 2700528, Tel 94I5842475, Email abunasaramu@gmail.com

Received: June 13, 2018| Published: August 07, 2018

\section{Introduction}

Water pollution has become a serious hazard to the environment these days. With the rapid growth of industrialization in the past few decades, the release of effluents into the water bodies has increased tremendously. The occurrence of varieties of pollutants such as heavy metals, dyes, pesticides, etc. continuously deteriorates the quality of water and become serious threats to the human health. ${ }^{1-6}$ One of the major sources of water contamination worldwide is the textile industries introducing dyes into water bodies. Further, dyes have become indispensable tools for a variety of industries such as food, paint, paper and pulp, ceramics, cosmetics, glass, medicine, rubber, printing ink, leather, textiles, etc. to color their products. In most cases, the presence of an even minute quantity of dye is clearly visible affecting aesthetic nature, thereby, reducing transparency and solubility of gases in water bodies. Photosynthetic activity of the aquatic flora is severely affected due to low penetration of light. Fauna is also extremely affected by the presence of dyes and the extent of damage depends on the concentration of dye as well as on the span of exposure. Also, synthetic dyes and their breakdown products such as benzidine, naphthalene, etc. are toxic, carcinogenic and mutagenic and have deteriorating effects on living organisms. Thus, the removal of dyes from the industrial effluents before it is discharged in the freshwater systems has become a challenge for us.

A wide variety of techniques such as electrodialysis, photocatalysis, ozonation, coagulation-flocculation, nanofiltration membranes, reverse osmosis, colloidal manganese dioxide oxidation, combined photo-Fenton and biological oxidation, etc. have been developed for the treatment of contaminated water containing pollutants such as dyes, heavy metals, pesticides and other organic impurities..$^{7-15}$ Out of these methods, adsorption has been observed to be the most attractive one because this method is easy, effective, eco-friendly and economical for the decontamination of dye-loaded effluents. However, all these techniques have their own merits and demerits. Among them, adsorption technique is considered to be preferable due to a number of factors such as initial cost, ease of operation, flexibility and simplicity of design, insensitivity to toxic pollutants and lower interference from diurnal variations. In fact, adsorption is economically efficient and environmentally benign technique. The economic feasibility of adsorption depends upon the choice of the adsorbent. Activated carbon has been most widely used as a conventional adsorbent because of its large surface area (up to $3000 \mathrm{~m}^{2} \mathrm{~g}^{-1}$ ), high porosity and high adsorbent capacity for a variety of pollutants. ${ }^{16,17}$ But, the high cost of production of activated carbons reduces its economic feasibility. Also, activated carbon become exhausted after first use and has to be reactivated which in turn result in 10-15\% loss of the adsorbent. Thus, the search for efficient and low-cost adsorbents has increased tremendously in the recent years. A literature survey showed that researchers have developed and used a wide variety of low-cost adsorbents for the removal of dyes. Some notable examples are almond shells, ${ }^{18}$ Citrus limetta peel, ${ }^{19}$ cottonseed hull, ${ }^{20}$ Cucumis sativus peel, ${ }^{21}$ egg shells,,${ }^{22}$ eucalyptus bark, ${ }^{23}$ Indian rosewood sawdust, ${ }^{24}$ neem leaf powder, ${ }^{25}$ mango seed, ${ }^{26}$ orange peel, ${ }^{27-29}$ peanut hull, ${ }^{30}$ pomelo peel, ${ }^{31,32}$ Psidium guajava leaf, ${ }^{33}$ shaddock peel, ${ }^{34}$ Terminalia arjuna sawdust, ${ }^{35}$ Tectona grandis sawdust,${ }^{36}$ wheat bran, ${ }^{37}$ etc.

Punica granatum is a deciduous shrub belonging to family Punicaceae. It is a native from Iran to the Himalayas in northern India and has been cultivated since ancient times throughout the Mediterranean region of Asia, Africa, and Europe. This fruit, locally known as pomegranate (anaar), is juicy and refreshing with a sub-acid pleasant taste. The fruit juice can be used in soups, jellies, ice creams, cakes, other sweet dishes, etc. The fruit has achieved preferred choice due to its delicious taste and high content of many nutrients such as dietary fiber, iron, potassium, vitamins $\mathrm{C}$ and $\mathrm{K}$, etc. It has been used in natural and holistic medicines to treat throat infection, cough, urinary infections, digestive disorders, skin disorders and arthritis. The peels of Punica granatum fruit are usually discarded as waste which could be better used as an adsorbent for the purification of water in the water treatment process. In the present work, the efficacy of Punica granatum peel (PGP) as a non-conventional low-cost adsorbent for 
the removal of methylene blue (MB) dye from aqueous solution has been investigated.

\section{Experimental}

\section{Solutions and reagents}

Analytical grade reagents- sodium hydroxide ( $\mathrm{CDH}$, India), potassium nitrate (CDH, India), hydrochloric acid (Merck, Germany), sodium chloride ( $\mathrm{CDH}$, India) and acetic acid (SD Fine, India) were used in the present work. De-ionized doubly distilled water (DDDW) was used to prepare the solutions throughout the investigation.

Methylene blue (MB) dye, obtained from Loba-Chemie, India was used as adsorbate without further purification. A stock solution of MB dye (1000 $\left.\mathrm{mg} \mathrm{L}^{-1}\right)$ prepared by dissolving accurately weighed quantity of MB in DDDW was used to prepare the solution of desired concentration as and when required.

\section{Preparation and characterization of adsorbent}

PGP, collected from local fruit vendors, was washed several times with DDDW to remove dust particles and other impurities present on its surface. The peels were then dried in sunlight for 5 days until they become crispy. Thereafter, the sun-dried peels were kept in an oven at about $95^{\circ} \mathrm{C}$ for $24 \mathrm{~h}$ to remove any possible moisture. The dried peels were then crushed into fine powder in a mixer grinder and sieved through $80 \mathrm{BSS}$ mesh. The powder mass was finally washed with DDDW until the complete removal of color and turbidity. This washed adsorbent was dried in an air oven at $90^{\circ} \mathrm{C}$ for $48 \mathrm{~h}$. The dried mass was crushed again and screened through a set of sieves to get different sized fractions, viz., 80-150, 150-200 and >200BSS which were stored in airtight containers.

The adsorbent was characterized using FTIR spectrometer to investigate the functional groups present in it. The morphological characteristics of PGP and MB-loaded PGP were observed using Scanning Electron Microscopy (SEM) (JOEL, JSM6510LV, Japan).

\section{Equilibrium experiments}

Batch adsorption experiments were carried out in $100 \mathrm{~mL}$ conical flasks of borosilicate glass at room temperature. The equilibrium experiments were conducted to estimate the efficacy of PGP as an adsorbent for the removal of MB from the artificially contaminated water. A fixed amount of PGP adsorbent $(0.2 \mathrm{~g})$ was added to $25 \mathrm{~mL}$ of $\mathrm{MB}$ solutions with varying initial concentrations ranging from $25 \mathrm{mg} \mathrm{L}^{-1}$ to $250 \mathrm{mg} \mathrm{L}^{-1}$. The samples were agitated in a rotary shaker at $25^{\circ} \mathrm{C}$ for $4 \mathrm{~h}$ and then filtered. The residual concentration of MB in the filtrate was determined spectrophotometrically by using UVVIS spectrophotometer at a pre-calibrated wavelength of $665 \mathrm{~nm}$. The adsorption capacity $\left(\mathrm{q}_{\mathrm{e}}\right)$ i.e. amount of dye adsorbed per unit mass of the adsorbent $\left(\mathrm{mg} \mathrm{g}^{-1}\right)$ was calculated by using the following equation:

$$
\mathrm{q}_{\mathrm{e}}=\frac{\mathrm{C}_{0}-\mathrm{C}_{\mathrm{e}}}{\mathrm{m}} \mathrm{V}
$$

Where $\mathrm{C}_{\mathrm{o}}$ and $\mathrm{C}_{\mathrm{e}}$ are the initial and equilibrium concentrations of $\mathrm{MB}, \mathrm{V}$ is the volume (L) of MB dye solution taken and $\mathrm{m}$ is the mass (g) of PGP adsorbent.

The removal efficiency $(\% \mathrm{R})$ of dye was calculated using the equation:

$$
\% \mathrm{R}=\frac{\mathrm{C}_{0}-\mathrm{C}_{\mathrm{e}}}{\mathrm{C}_{0}} \times 100
$$

The effect of various parameters such as adsorbent dosage, contact time, particle size, $\mathrm{pH}$ and temperature were studied in a similar manner and were optimized to obtain the maximum removal of $\mathrm{MB}$ dye. Point of zero charge $\left(\mathrm{pH}_{\mathrm{pzc}}\right)$ of the adsorbent was determined using solid addition method. ${ }^{38}$ A series of $45 \mathrm{~mL}$ solutions of $0.1 \mathrm{~N} \mathrm{KNO}_{3}$ were taken in $100 \mathrm{~mL}$ conical flask and $\mathrm{pH}$ values were adjusted in the range of 2-12. The $\mathrm{pH}$ values of the solutions were adjusted using $0.1 \mathrm{~N} \mathrm{HCl}$ and $0.1 \mathrm{~N} \mathrm{NaOH}$. After that the volume of the solution was made up to $50 \mathrm{~mL}$ by adding the same solution. Pre-weighed samples of PGP $(0.1 \mathrm{~g})$ were added to each flask and the solutions were agitated for $48 \mathrm{~h}$ and final $\mathrm{pHs}\left(\mathrm{pH}_{\mathrm{f}}\right)$ of the solutions were determined using a $\mathrm{pH}$ meter. The point at which the line in the $\Delta \mathrm{pH}$ (i.e. $\mathrm{pH}_{\mathrm{f}}-\mathrm{pH}_{\mathrm{i}}$ ) $\mathrm{vs}_{\mathrm{pH}}$ graph cross the $\mathrm{x}$-axis gives the value of $\mathrm{pH}_{\mathrm{pzc}}$.

\section{Isotherm modeling}

Langmuir, Freundlich and Temkin isotherm models were employed in the present study for analyzing the equilibrium data obtained. Langmuir adsorption isotherm model is based on the assumption that the surface of the adsorbent is uniform (all the sites are equivalent) with a finite number of adsorption sites. Only monolayer adsorption takes place and once the site is occupied, no further adsorption can take place on that site resulting in the saturation of the adsorbent surface. ${ }^{39}$ The linearized mathematical form of this model can be expressed as: ${ }^{40}$

$$
\frac{1}{\mathrm{q}_{\mathrm{e}}}=\frac{1}{\mathrm{~K}_{\mathrm{L}} \mathrm{C}_{\mathrm{e}} \mathrm{q}_{\mathrm{m}}}+\frac{1}{\mathrm{q}_{\mathrm{m}}}
$$

where, $\mathrm{q}_{\mathrm{e}}\left(\mathrm{mg} \mathrm{g}^{-1}\right)$ is the adsorption capacity of the adsorbent, $\mathrm{K}_{\mathrm{L}}(\mathrm{L}$ $\left.\mathrm{mg}^{-1}\right)$ is the Langmuir constant related to the adsorption energy, $\mathrm{q}_{\mathrm{m}}(\mathrm{mg}$ $\mathrm{g}^{-1}$ ) is the maximum adsorption capacity and $\mathrm{C}_{\mathrm{e}}$ is the concentration of adsorbate at equilibrium.

Freundlich adsorption isotherm is an empirical equation which assumes the surface of the adsorbent to be heterogeneous. ${ }^{41}$ This isotherm in its linear form is expressed as:

$$
\ln \mathrm{q}_{\mathrm{e}}=\ln \mathrm{K}_{\mathrm{F}}+\frac{1}{\mathrm{n}} \ln \mathrm{C}_{\mathrm{e}}
$$

where, $\mathrm{K}_{\mathrm{F}}$ is the Freundlich constant representing the adsorption capacity at equilibrium and $\mathrm{n}$ indicates the intensity of adsorption.

The Temkin isotherm model, ${ }^{42}$ based on the assumption that the heat of adsorption decreases linearly with the coverage because of the adsorbate-adsorbent interactions, can be expressed in the following linear form.

$$
\mathrm{q}_{\mathrm{e}}=\mathrm{B} \ln \mathrm{K}_{\mathrm{T}}+\mathrm{B} \ln \mathrm{C}_{\mathrm{e}}
$$

where, $\mathrm{B}=\mathrm{RT} / \mathrm{b}$. $\mathrm{B}$ is the Temkin constant representing the heat of adsorption $\left(\mathrm{J} \mathrm{mol}^{-1}\right), \mathrm{K}_{\mathrm{T}}$ is the equilibrium binding constant $\left(\mathrm{L} \mathrm{g}^{-1}\right), \mathrm{b}$ is Temkin isotherm constant, $\mathrm{R}$ is gas constant $\left(8.314 \mathrm{~J} \mathrm{~K}^{-1} \mathrm{~mol}^{-1}\right)$ and $\mathrm{T}$ is temperature $(\mathrm{K})$. The values of $\mathrm{B}$ and $\mathrm{K}_{\mathrm{T}}$ can be calculated from the slope and intercept of $\mathrm{q}_{\mathrm{e}}$ versus $\ln \mathrm{C}_{\mathrm{e}}$ plot. 


\section{Kinetic studies}

To study the kinetics of the adsorption of MB onto PGP, $0.2 \mathrm{~g}$ of PGP was added to $25 \mathrm{~mL}$ for time periods ranging from $5-240 \mathrm{~min}$. The change in concentration of MB with time was observed spectrophotometrically by the same procedure as in batch adsorption studies. The amount of dye adsorbed was calculated using an equation similar to Eq. (1) where $\mathrm{q}_{\mathrm{e}}$ and $\mathrm{C}_{\mathrm{e}}$ are replaced by $\mathrm{q}_{\mathrm{t}}$ and $\mathrm{C}_{\mathrm{t}}$ respectively, where ' $t$ ' represents the respective values at any time. To explain the mechanism of adsorption, the kinetic data were analyzed in the light of pseudo-first order, pseudo-second order, intraparticle diffusion, and Elovich models. The mathematical form of pseudofirst order, ${ }^{43}$ pseudo-second order ${ }^{44,45}$ intraparticle diffusion ${ }^{46}$ and Elovich ${ }^{47}$ models are expressed as:

$$
\begin{aligned}
& \ln \left(\mathrm{q}_{\mathrm{e}}-\mathrm{q}_{\mathrm{t}}\right)=\ln \mathrm{q}_{\mathrm{e}}-\mathrm{k}_{1} \mathrm{t} \\
& \frac{\mathrm{t}}{\mathrm{q}_{\mathrm{e}}}=\frac{1}{\mathrm{k}_{2} \mathrm{q}_{e}^{2}}+\frac{\mathrm{t}}{\mathrm{q}_{\mathrm{e}}} \\
& \mathrm{q}_{\mathrm{t}}=\mathrm{K}_{\mathrm{id}} \mathrm{t}^{1 / 2}+\mathrm{C} \\
& \mathrm{q}_{\mathrm{t}}=\frac{1}{\beta} \ln (\alpha \beta)+\frac{1}{\beta} \ln \mathrm{t}
\end{aligned}
$$

where, $\mathrm{k}_{1}$ is the rate constant $\left(\mathrm{min}^{-1}\right)$ of pseudo-first order reaction, $\mathrm{k}_{2}$ is pseudo-second-order rate constant $\left(\mathrm{g} \mathrm{mg}^{-1} \mathrm{~min}^{-1}\right), \mathrm{K}_{\mathrm{id}}$ is intraparticle diffusion rate constant $\left(\mathrm{mg} \mathrm{g}^{-1} \mathrm{~min}^{-1 / 2}\right), \mathrm{C}$ is the thickness of the boundary layer, $\alpha$ is the initial rate of adsorption $\left(\mathrm{mg} \mathrm{g}^{-1} \mathrm{~min}^{-}\right.$ $\left.{ }^{1}\right)$ and $\beta$ is related to surface coverage $\left(\mathrm{g} \mathrm{mg}^{-1}\right), \mathrm{q}_{\mathrm{t}}$ is the adsorption capacity $\left(\mathrm{mg} \mathrm{g}^{-1}\right)$ at time $\mathrm{t}$ and $\mathrm{q}_{\mathrm{e}}$ is the adsorption capacity $\left(\mathrm{mg} \mathrm{g}^{-1}\right)$ at equilibrium.

\section{Thermodynamic studies}

To explain the thermodynamic behavior of MB adsorption onto PGP adsorbent, $0.2 \mathrm{~g}$ of PGP was added to $25 \mathrm{~mL} 100 \mathrm{mg} / \mathrm{L}$ of $\mathrm{MB}$ and agitated in a temperature-controlled water-bath shaker at 293, 303, 313 and $323 \mathrm{~K}$ for $1 \mathrm{~h}$. The samples were filtered and the extent of adsorption was estimated spectrophotometrically. Enthalpy change $\left(\Delta \mathrm{H}^{\circ}\right)$, entropy change $\left(\Delta \mathrm{S}^{\circ}\right)$ and Gibbs free energy change $\left(\Delta \mathrm{G}^{\circ}\right)$ were calculated using the following equations:

$$
\begin{aligned}
& \Delta \mathrm{G}^{\circ}=-\mathrm{RT} \ln \mathrm{K}_{\mathrm{C}} \\
& \ln \mathrm{K}_{\mathrm{C}}=\frac{\Delta \mathrm{H}^{\circ}}{\mathrm{RT}}=\frac{\Delta \mathrm{S}^{\circ}}{\mathrm{R}}=\frac{\Delta \mathrm{G}^{\circ}}{\mathrm{RT}}
\end{aligned}
$$

where, $R$ is gas constant, $K_{C}$ is equilibrium constant and $T$ is the temperature in the thermodynamic scale.

\section{Desorption studies}

The adsorption is associated with a secondary task which involves the regeneration of adsorbent and recovery of adsorbent. MB-loaded PGP was mildly washed with DDDW to remove any unadsorbed dye present and dried in an air oven at $30^{\circ} \mathrm{C}$ until completely dry. Desorption of MB-loaded PGP was studied with $0.1 \mathrm{~N} \mathrm{HCl}$ (strong acid), $0.1 \mathrm{~N} \mathrm{NaOH}$ (strong base), $0.1 \mathrm{~N} \mathrm{NaCl}$ (neutral salt), $0.1 \mathrm{~N}$ $\mathrm{CH}_{3} \mathrm{COOH}$ (weak acid) and DDDW. 0.2g of the MB-loaded PGP was added to $25 \mathrm{~mL}$ each of the desorbing reagents and was left for $4 \mathrm{~h}$. The amount of dye desorbed was determined spectrophotometrically at $665 \mathrm{~nm}$. Desorption percentage was calculated using the following equation:

$$
\% \text { Desorption }=\frac{\mathrm{m}_{\mathrm{d}}}{\mathrm{m}_{\mathrm{a}}} \times 100
$$

where, $\mathrm{m}_{\mathrm{a}}$ and $\mathrm{m}_{\mathrm{d}}$ are the amounts of MB dye adsorbed and desorbed, respectively.

\section{Results and discussion \\ SEM and FTIR analyses}

SEM micrographs of PGP and MB-loaded PGP shown respectively in Figure 1 indicate that surface of unadsorbed PGP is uneven, porous with large circular fissures and clefts resulting in an amorphous assembly. After adsorption, the irregularities and pores on the surface of PGP are occupied by the MB dye up to a considerable extent (Figure 1B).

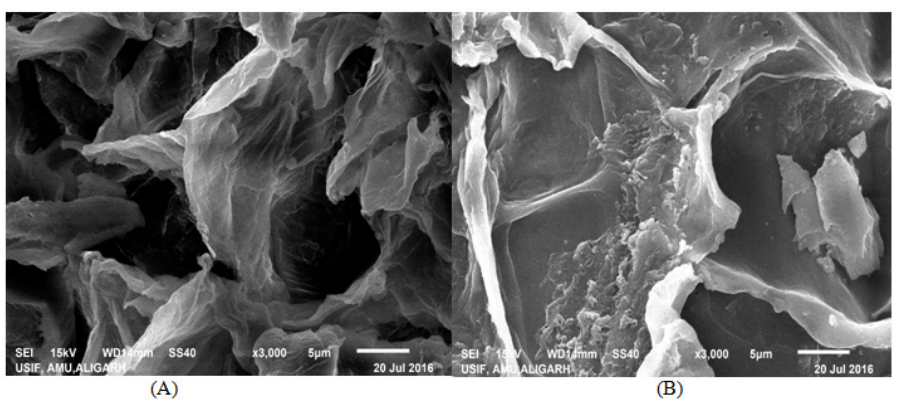

Figure I SEM micrographs $(\times 5000)$ of PGP $(A)$ before adsorption $(B)$ after adsorption with MB dye.

FTIR spectra of PGP and MB-loaded PGP are shown in Figure 2. The strong peak at $3434 \mathrm{~cm}^{-1}$ represents $\mathrm{O}-\mathrm{H}$ stretching vibration of alcohols (broadness of peak indicates H-bonding) whereas the peaks at $2916 \mathrm{~cm}^{-1}$ and $2840 \mathrm{~cm}^{-1}$ indicates the asymmetric and symmetric stretching vibration of aliphatic $-\mathrm{CH}_{3}$ or $-\mathrm{CH}_{2}$ groups. The peaks at $1728 \mathrm{~cm}^{-1}$ and $1624 \mathrm{~cm}^{-1}$ are attributed to $\mathrm{C}=\mathrm{O}$ stretching vibration of the carbonyl group (may be aldehyde or ester) and symmetric stretching vibration of the $\mathrm{C}=\mathrm{C}$ bond, respectively. The peaks in the range $1500-1300 \mathrm{~cm}^{-1}$ (i.e. $1434 \mathrm{~cm}^{-1}$ and $1392 \mathrm{~cm}^{-1}$ ) specifies $\mathrm{H}-\mathrm{C}-\mathrm{H}$ bending vibration of the methyl group. The peak at $1234 \mathrm{~cm}^{-1}$ signifies the $\mathrm{C}-\mathrm{O}$ stretching vibration supporting the existence of carboxyl/ alcohol/ether/ester functional groups in the adsorbent. The presence of aliphatic fluoro compounds is established by the peak at $1012 \mathrm{~cm}^{-1}$ in the FTIR spectrum of PGP. The peaks in the ranges $915-850 \mathrm{~cm}^{-}$ ${ }^{1}\left(867 \mathrm{~cm}^{-1}\right)$ and $790-650 \mathrm{~cm}^{-1}\left(658 \mathrm{~cm}^{-1}\right)$ might be due to the $-\mathrm{C}-\mathrm{H}$ bending vibration of the alkene. On comparing the spectra of the two samples i.e. PGP and MB-loaded PGP, a slight shifting in the peaks from $3434 \mathrm{~cm}^{-1}$ to $3446 \mathrm{~cm}^{-1}, 1624 \mathrm{~cm}^{-1}$ to $1636 \mathrm{~cm}^{-1}$ and $1234 \mathrm{~cm}^{-1}$ to $1260 \mathrm{~cm}^{-1}$ along with the reduction of peak intensities was observed in MB-loaded PGP. This indicates the participation of the respective groups (alcoholic/carboxyl/ether/ester/alkene) in the adsorption of MB onto PGP. Being a small atomic size and high electronegativity the $\mathrm{N}$ atom present in $\mathrm{MB}$ dye have the potential to form the $\mathrm{H}$ bond 
with OH group present in PGP. The adsorption of MB on PGP may also occur presumably due to the formation of $\mathrm{H}$ bond.

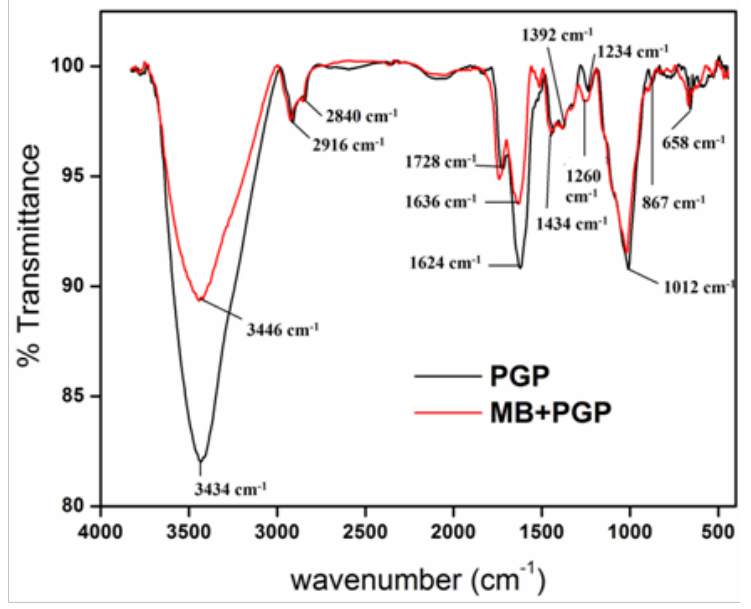

Figure 2 FTIR spectra of PGP and MB-loaded PGP.

\section{Effect of contact time}

The variation of adsorption capacity $\left(q_{e}\right)$ with time for the adsorption of MB onto PGP is shown in Figure 3. It is apparent from the figure that the removal efficiency first rises rapidly in the early stage $(0-30 \mathrm{~min})$, gradually slows down after $30 \mathrm{~min}$ and lastly becomes constant after $180 \mathrm{~min}$. The rapid increase in adsorption in the initial stage is due to the accessibility of a large number of active sites on the peripheral surface of the adsorbent on which MB molecules get adsorbed through boundary layer adsorption. ${ }^{48}$ As the time is increased, the surface of the adsorbent gets saturated progressively with MB molecules. In the later stage, MB molecules get diffused into the pores of PGP which slows down the process of adsorption. Finally, when all the sites are occupied with dye molecules, the remaining dye molecules form aggregates at higher contact time. ${ }^{49}$ Thus, the equilibrium time for the MB-PGP system was judiciously taken to be $3 \mathrm{~h}$. It is also concluded from Figure 3 that the adsorption capacity increases with the increase in the concentration of $\mathrm{MB}$ from $25 \mathrm{mg}$ $\mathrm{L}^{-1}$ to $250 \mathrm{mg} \mathrm{L}^{-1}$. A linear relationship between $\mathrm{q}_{\mathrm{e}}$ and $\mathrm{C}_{\mathrm{e}}$ has been obtained with $\mathrm{R}^{2}=0.9999$ and represented by the following equation:

$$
\mathrm{q}_{\mathrm{e}}=0.1215 \mathrm{C}_{\mathrm{e}}-1.5842
$$

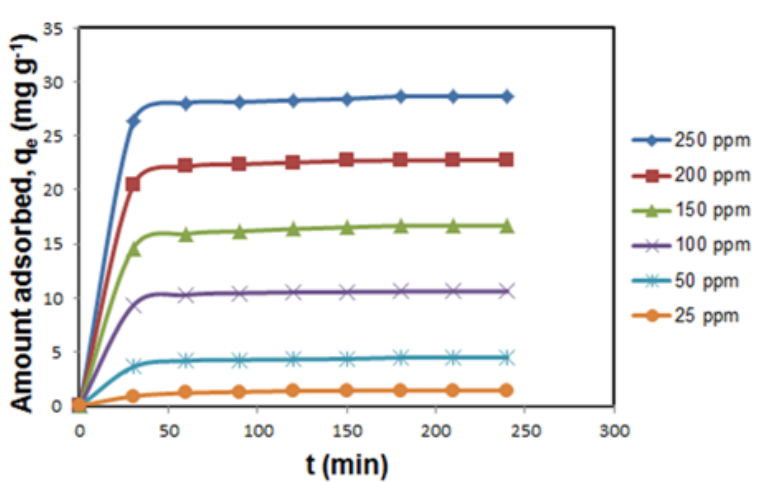

Figure 3 Effect of contact time on adsorption capacity for the adsorption of MB onto PGP adsorbent.

\section{Effect of adsorbent dosage}

The effect of adsorbent dosage on the adsorption of MB was studied for different quantities of PGP $\left(0.2-11 \mathrm{~g} \mathrm{~L}^{-1}\right)$. The results are presented in Figure 4. It can be clearly seen from the figure that the removal efficiency increases from $37.2 \%$ to $76.5 \%$ with the increase in PGP dosage from 0.1 to $8 \mathrm{~g} \mathrm{~L}^{-1}$. Subsequently, there is no major change in the removal efficiency with a further increase in adsorbent dosage. The optimum adsorbent dosage for MB-PGP system was found to be $8 \mathrm{~g} \mathrm{~L}^{-1}$. The increase in adsorption of $\mathrm{MB}$ with the increase in adsorbent dosage is due to the availability of a large number of active sites and large surface area.

Conversely, the reverse trend was observed in case of variation of adsorption capacity with adsorbent dosage. This behavior might be due to the saturation of the adsorption sites because of particulate interactions such as aggregation which results in a decrease in the overall surface area of the adsorbent. ${ }^{19}$

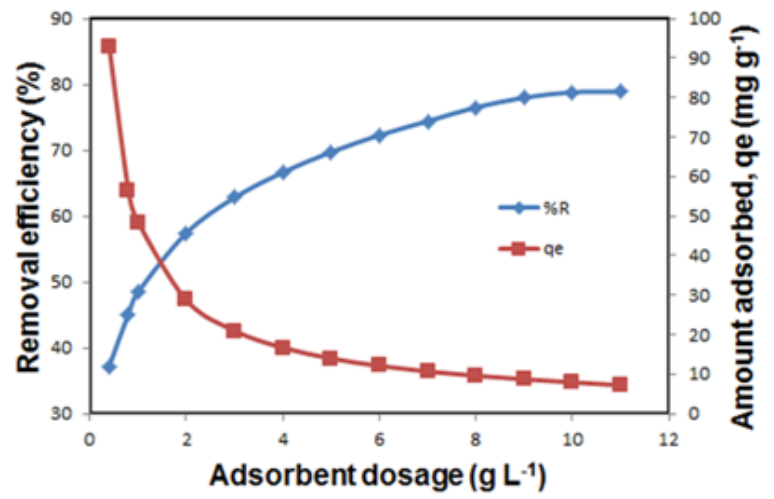

Figure 4 Effect of PGP dosage on the adsorption capacity and removal efficiency.

\section{Effect of particle size}

The effect of particle size of the adsorbent on MB adsorption is shown in Figure 5. It can be clearly seen from the figure that the removal efficiency increases from $84.1 \%$ to $92.7 \%$ in decreasing the particle size from $80-150$ BSS to $>200 \mathrm{BSS}$. The reason for this behavior might be the increase in the surface area of the adsorbent and availability of a large number of active sites for adsorption. But, due to the handling difficulties accompanying smaller particle size, particles in the range of $80-150$ BSS were selected for the MB-PGP adsorption studies.

\section{Effect of pH}

$\mathrm{pH}$ is an important factor which affects the process of adsorption. Figure 6 shows the effect of $\mathrm{pH}$ on the adsorption of MB by PGP at $100 \mathrm{mg} \mathrm{L}^{-1}$ initial MB concentration. It can be seen from the figure that the adsorption of $\mathrm{MB}$ is $54.9 \%$ at $\mathrm{pH}$ value 2 . The removal efficiency increased with the increase in the solution $\mathrm{pH}$ and reached up to $83.5 \%$ at $\mathrm{pH}=7$. However, there is no further increase in the removal efficiency above the $\mathrm{pH}$ value of 7 . At low $\mathrm{pH}$ values, the surface of the adsorbent becomes positively charge by the absorption of $\mathrm{H}^{+}$ ions leading to repulsion between cationic $\mathrm{MB}$ and positively charged adsorbent. Also, there is competition between $\mathrm{H}^{+}$and $\mathrm{MB}$ molecules for the active sites on PGP. Similar observations were reported in the literature for MB-wheat shell ${ }^{50}$ and MB-yellow passion fruit peel ${ }^{51}$ adsorbate-adsorbent systems. 


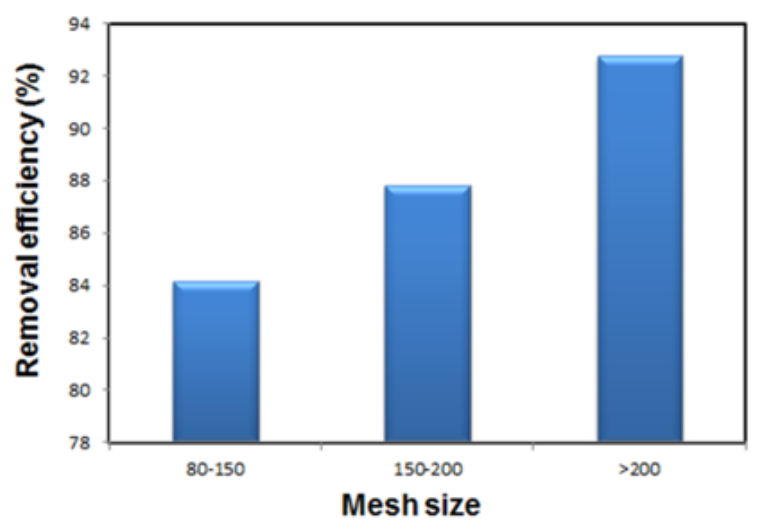

Figure 5 Effect of particle size on MB adsorption with PGP.

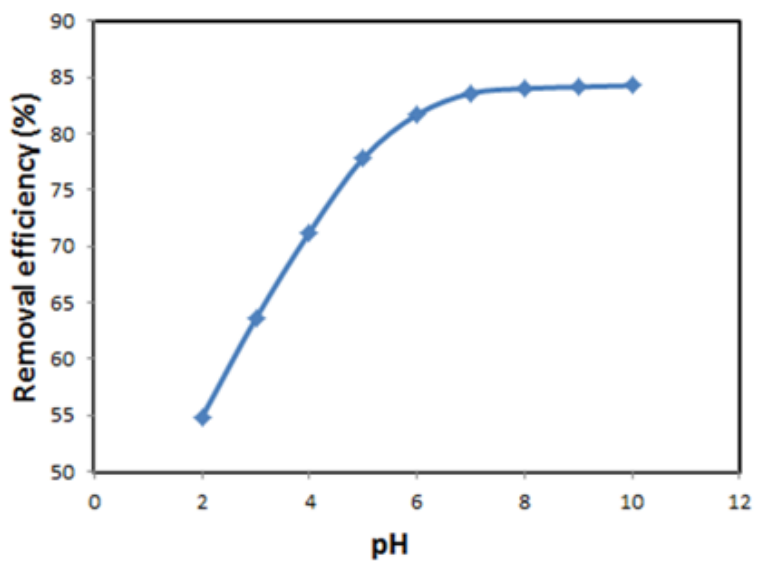

Figure 6 Effect of $\mathrm{pH}$ on the removal of MB by PGP.

The effect of $\mathrm{pH}$ of the solution on the adsorption of $\mathrm{MB}$ can also be clarified using the information of the point of zero charge ( $\mathrm{pHpzc}$ ). The point of zero charge for the MB-PGP system was found to be 5.73 (Figure 7). For $\mathrm{pH}<\mathrm{pHpzc}$, the surface of the PGP adsorbent acquire positive charge whereas at $\mathrm{pH}>\mathrm{pHpzc}$, the surface acquires a negative charge. As MB is a cationic dye and the surface of PGP should be negatively charged for adsorption to occur, the $\mathrm{pH}$ of the solution should $>5.73$. Consequently, an optimum $\mathrm{pH}=7$ is selected for the adsorption study.

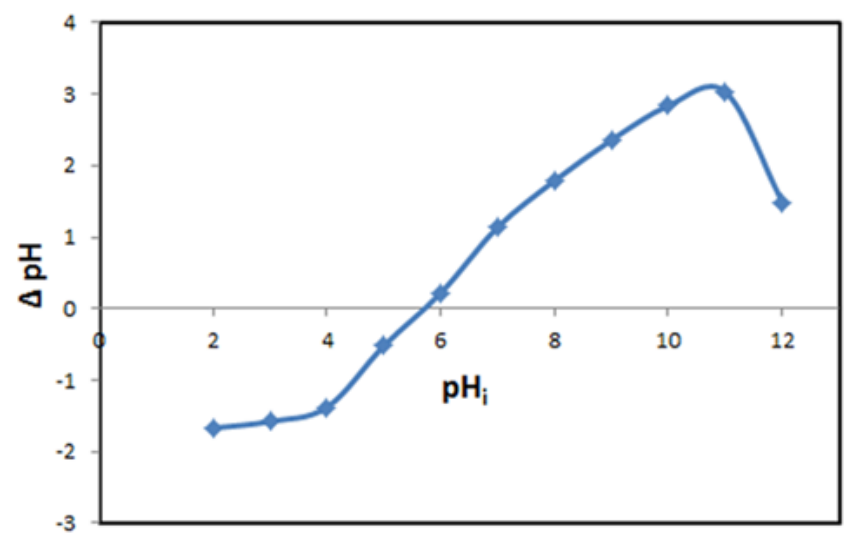

Figure 7 Point of zero charge for PGP adsorbent.

\section{Equilibrium studies}

In the present study, the equilibrium data were analyzed in the light of well-established isotherms, namely, Langmuir, Freundlich and Temkin isotherm models. The Langmuir adsorption isotherm model does not fit the experimental data and is inadequate to be used in this case. The linear plot of $\ln \mathrm{C}_{e}$ vs. $\mathrm{q}_{e}$ (Figure 8) clearly shows that the adsorption obeys Temkin isotherm model. The value of the coefficient of correlation $\left(\mathrm{R}^{2}=0.9872\right)$ obtained from Temkin isotherm model shows that this model offers a better fit to the experimental data. According to the Temkin adsorption isotherm model, there is a high probability that the active sites on the surface of the unmodified natural adsorbent might be energetically non-equivalent. The more energetic active sites of the adsorbent are occupied first in the process of adsorption. ${ }^{52}$

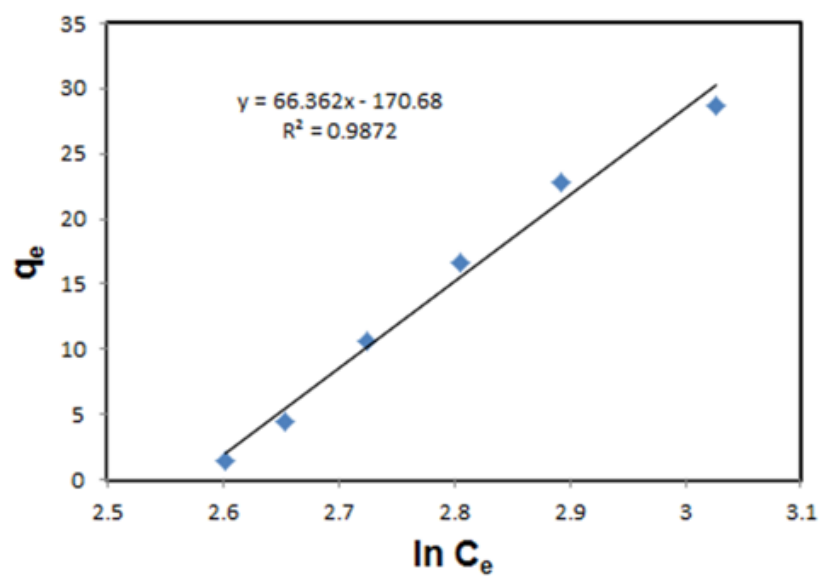

Figure 8 Temkin adsorption isotherm for MB-PGP system at 298K.

\section{Kinetic studies}

For understanding the kinetics of MB-PGP system, the kinetic data was analyzed in the light of pseudo-first order, pseudo-second order, Elovich and intraparticle diffusion models. The values of the various constants for the various kinetic models and their respective correlation coefficients are presented in Table 1. This table clearly tells that the pseudo-second-order kinetic model (Figure 9) fits the experimental data with an excellent $\mathrm{R}^{2}$ value of 0.9998 .

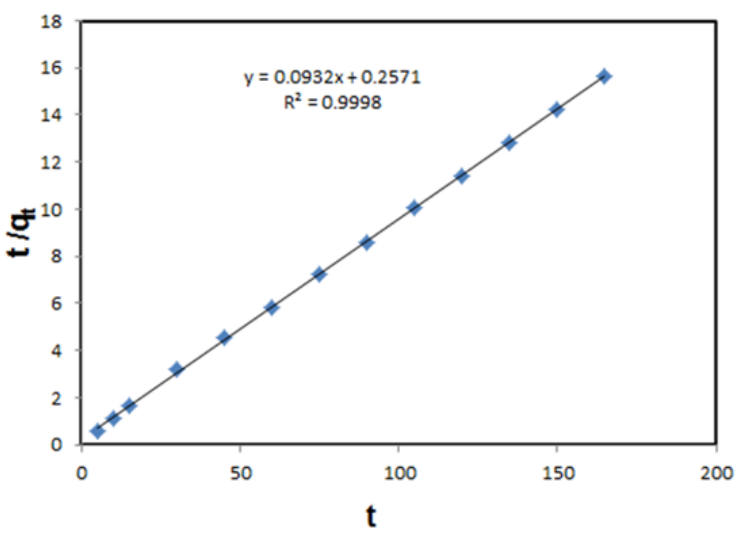

Figure 9 Pseudo-second order kinetic model for the adsorption of MB onto PGP (100mg L-1) 
Table I Kinetic study for the adsorption of MB onto PGPP adsorbent (Reaction conditions: $\mathrm{C}_{0}=100 \mathrm{mg} \mathrm{L}^{-1}$, Adsorbent dose $=8 \mathrm{~g} \mathrm{~L}^{-1}$, Temperature $=298 \mathrm{~K}, \mathrm{pH}=7$ )

\begin{tabular}{|c|c|}
\hline Kinetic models & Values \\
\hline \multicolumn{2}{|l|}{ Pseudo-first order } \\
\hline $\mathrm{k}_{\mathrm{l}}$ & 0.0273 \\
\hline$q_{e, \exp }$ & 10.5929 \\
\hline $\mathrm{q}_{\mathrm{e}, \mathrm{cal}}$ & 2.2042 \\
\hline $\mathrm{R}^{2}$ & 0.9768 \\
\hline \multicolumn{2}{|c|}{ Pseudo-second order } \\
\hline $\mathrm{k}_{2}$ & 0.0337 \\
\hline$q_{e, \exp }$ & 10.5929 \\
\hline $\mathrm{q}_{\mathrm{e}, \mathrm{cal}}$ & 10.7296 \\
\hline $\mathrm{R}^{2}$ & 0.9998 \\
\hline \multicolumn{2}{|c|}{ Intraparticle diffusion } \\
\hline $\mathrm{K}_{\mathrm{id}}$ & 0.1904 \\
\hline $\mathrm{C}$ & 8.4204 \\
\hline $\mathrm{R}^{2}$ & 0.9124 \\
\hline \multicolumn{2}{|l|}{ Elovich } \\
\hline$\alpha$ & $1.179 \times 10^{5}$ \\
\hline$\beta$ & 1.6157 \\
\hline $\mathrm{R}^{2}$ & 0.9528 \\
\hline
\end{tabular}

Pseudo-first order kinetic model is not obeyed as the data does not fall on the straight line. The values of $\mathrm{q}_{\mathrm{e}, \text { cal }}$ and $\mathrm{q}_{\mathrm{e}, \mathrm{exp}}$ show marked differences and the value of the correlation coefficient is comparatively low. Thus, the pseudo-first order kinetic model is inapt for this system. For the pseudo-second-order kinetic model, the values of theoretical $\mathrm{q}_{\mathrm{e}}$ value $\left(\mathrm{q}_{\mathrm{e}, \text { cal }}\right)$ and experimental $\mathrm{q}_{\mathrm{e}}$ value $\left(\mathrm{q}_{\mathrm{e} \text { exp }}\right)$ are very close to each other. Also, the value of the correlation coefficient is found to be close to $1\left(\mathrm{R}^{2}=0.9998\right)$. The plot of intraparticle diffusion model did not pass through origin signifying that intraparticle diffusion is not the only rate-limiting step and some other mechanism is involved in the MB adsorption process. The value of the correlation coefficient for this model is quite absurd (0.9124). For the Elovich model, the value of the coefficient of correlation is 0.9528 . The values of $\alpha$ and $\beta$ are given in Table 1.

By comparing the $\mathrm{R}^{2}$ values for the various models, it is concluded that the best fit kinetic model for the adsorption of MB onto PGP is pseudo-second-order model $\left(\mathrm{R}^{2}=0.9998\right)$.

\section{Adsorption thermodynamics}

The results of the thermodynamic studies indicated that the removal efficiency increases with the increase of temperature ranging from $293 \mathrm{~K}$ to $323 \mathrm{~K}$. Thermodynamic parameters such as enthalpy change $\left(\Delta \mathrm{H}^{\circ}\right)$, entropy change $\left(\Delta \mathrm{S}^{\circ}\right)$ and Gibbs free energy change $\left(\Delta \mathrm{G}^{\circ}\right)$ were calculated for MB-PGP system (Table 2$)$. This table clearly indicates that the process is endothermic and associated with the enhancement of entropy.
Table 2 Thermodynamic parameters for the adsorption of MB onto PGP (Reaction conditions: $\mathrm{Co}=100 \mathrm{mg} \mathrm{L}^{-1}$, Adsorbent dose $=8 \mathrm{~g} \mathrm{~L}^{-1}, \mathrm{t}=3 \mathrm{~h}, \mathrm{pH}=7$ )

\begin{tabular}{llll}
\hline $\begin{array}{l}\text { Temperature } \\
(\mathbf{K})\end{array}$ & $\left.\Delta \mathbf{G}^{0}(\mathbf{k J ~ m o l})^{-1}\right)$ & $\left.\Delta \mathbf{H}^{0}(\mathbf{k J ~ m o l})^{-1}\right)$ & $\Delta \mathbf{S}^{0}\left(\mathbf{J ~ K}^{-1} \mathbf{m o l}^{-1}\right)$ \\
\hline 293 & -1.74 & 31.29 & 113.13 \\
303 & -2.96 & & \\
313 & -4.54 & & \\
323 & -4.95 & & \\
\hline
\end{tabular}

A negative value of $\Delta \mathrm{G}^{\circ}$ signifies that the adsorption process is feasible and spontaneous within the temperature range selected in the present investigation. The values of $\Delta \mathrm{H}^{\circ}$ and $\Delta \mathrm{S}^{\circ}$ determined from the slope and intercept of $\ln \mathrm{k}_{\mathrm{c}}$ versus $1 / \mathrm{T}$ plot (Figure 10). A positive value of $\Delta \mathrm{H}^{\circ}$ shows that the reaction is endothermic in nature. The positive value of $\Delta \mathrm{S}^{\circ}$ indicates the increase in the randomness at the adsorbate/solution interface during MB adsorption. ${ }^{53}$ The increase in entropy might be due to increase in translational energy of the dye molecules. The increase in entropy has also been reported in the literature for the adsorption of MB onto fallen leaves of Platanus, ${ }^{54}$ illitic clay mineral, ${ }^{53}$ Citrus limetta peel, ${ }^{19}$ wheat shells, ${ }^{50}$ etc.

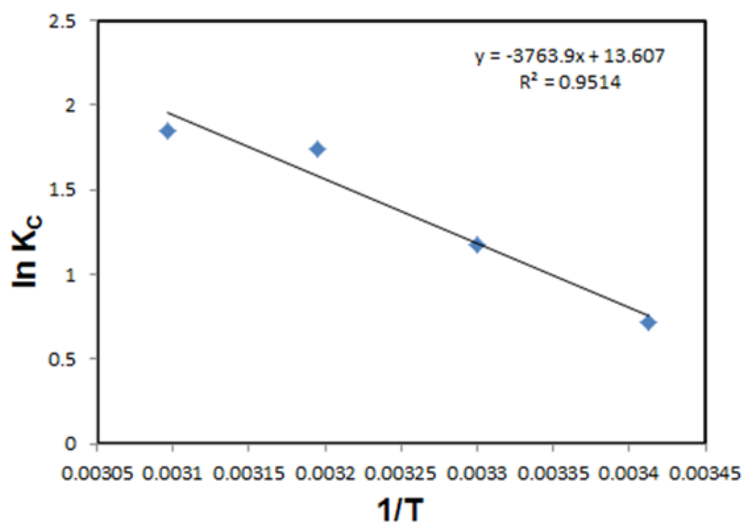

Figure 10 Effect of temperature on the adsorption of MB onto PGP.

\section{Desorption}

The study of the desorption process helps to understand the mechanism of adsorption and also the possibility of retrieval of adsorbate as well as an adsorbent. The treatment process will become economically advantageous, if the adsorbent could be regenerated successfully. Desorption of MB-loaded PGP was studied in five desorbing reagents and the percentage of desorption for each of them is given in Table 3.

Table 3 Desorption of MB from MB-loaded PGP in different media

\begin{tabular}{ll}
\hline Desorbing reagent & \% desorption \\
\hline $0.1 \mathrm{M} \mathrm{HCl}$ & 30.16 \\
$0.1 \mathrm{M} \mathrm{CH} \mathrm{COOH}_{3}$ & 21.9 \\
$0.1 \mathrm{M} \mathrm{NaOH}$ & 5.45 \\
$0.1 \mathrm{M} \mathrm{NaCl}$ & 20.09 \\
$D D D W$ & 5.14
\end{tabular}


It was found that the highest desorption takes place in $0.1 \mathrm{~N} \mathrm{HCl}$ (30.16\%) followed by $0.1 \mathrm{~N} \mathrm{CH}_{3} \mathrm{COOH}(21.91 \%)$ and least desorption is found in DDDW (5.14\%). Thus, it was inferred that $\mathrm{HCl}$ is the most appropriate desorbing reagent which enabled reusability of PGP making the overall process more economical.

\section{Conclusion}

In the present study, the effectiveness of PGP for the adsorptive removal of $\mathrm{MB}$ was in the batch method investigated. Batch adsorption studies reveal that the adsorption of MB onto PGP is affected by various parameters such as contact time, $\mathrm{pH}$, adsorbent dosage, the particle size of adsorbent and temperature. The optimum $\mathrm{pH}$ was found to be 7 which is verified by the point of zero charge experiment $\left(\mathrm{pH}_{\mathrm{pzc}}=5.73\right)$. The adsorption of MB onto PGP is best described by Temkin adsorption isotherm model. Thermodynamic studies revealed that the adsorption of MB onto PGP is feasible, spontaneous and endothermic accompanied by an increase in entropy. Regeneration of the used PGP was successfully achieved in $0.1 \mathrm{~N} \mathrm{HCl}$.

Thus, it was concluded that PGP, which is a waste material and is readily available, can be used for the removal of dyes from contaminated water.

\section{Acknowledgments}

The authors are grateful to the Chairman, Department of Applied Chemistry, Faculty of Engineering and Technology, Aligarh Muslim University for providing necessary laboratory facilities.

\section{Conflict of interest}

The author declares that there is no conflict of interest.

\section{References}

1. Kar D, Sur P, Mandai SK, et al. Assessment of Heavy Metal Pollution in Surface Water. International Journal of Environmental Science \& Technology. 2008;5(1):119-124.

2. Järup L. Hazards of Heavy Metal Contamination. Br Med Bull. 2003;68:167-182.

3. Qamruzzaman, Nasar A. Treatment of Acetamiprid Insecticide from Artificially Contaminated Water by Colloidal Manganese Dioxide in the Absence and Presence of Surfactants. RSC Advances. 2014;4(108):62844 62850 .

4. Qamruzzaman, Nasar A. Pesticides: Positive and Negative Aspects and Their Treatment in Wastewater. Materials Research Forum LLC; 2018. p. 195-213.

5. Schwarzenbach RP, Egli T, Hofstetter TB, et al. Global Water Pollution and Human Health. Annual Review of Environment and Resources. 2010;35(1):109-136.

6. Nasar A, Shakoor S. Remediation of Dyes from Industrial Wastewater Using Low-Cost Adsorbents. In: Inamuddin, Al-Ahmed A, editors. Applications of Adsorption and Ion Exchange Chromatography in Waste Water Treatment. Materials Research Forum LLC; 2017. p. 1-33.

7. Korngold E, Kock K, Strathmann H. Electrodialysis in Advanced Waste Water Treatment. Desalination. 1977;24(1-3):129-139.

8. Chong MN, Jin B, Chow CWK, et al. Recent Developments in Photocatalytic Water Treatment Technology: A Review. Water Research. 2010;44(10):2997-3027.

9. Lin SH, Lin CM. Treatment of Textile Waste Effluents by Ozonation and
Chemical Coagulation. Water Research. 1993;27(12):1743-1748.

10. Butani SA, Mane SJ. Coagulation/Flocculation Process for Cationic, Anionic Dye Removal Using Water Treatment Residuals- a Review. IJSTM. 2017;6(4):121-125.

11. Ivnitsky H, Katz I, Minz D, et al. Bacterial Community Composition and Structure of Biofilms Developing on Nanofiltration Membranes Applied to Wastewater Treatment. Water Research. 2007;41(17):3924-3935.

12. Greenlee LF, Lawler DF, Freeman BD, et al. Reverse Osmosis Desalination: Water Sources, Technology, and Today's Challenges. Water Research. 2009;43(9):2317-2348.

13. Qamruzzaman, Nasar A. Degradation of Acephate by Colloidal Manganese Dioxide in the Absence and Presence of Surfactants. Desalination and Water Treatment. 2015;55(8):2155-2164.

14. Qamruzzaman, Nasar A. Degradation of Tricyclazole by Colloidal Manganese Dioxide in the Absence and Presence of Surfactants. Journal of Industrial and Engineering Chemistry. 2014;20(3):897-902.

15. Qamruzzaman, Nasar A. Kinetics of Metribuzin Degradation by Colloidal Manganese Dioxide in Absence and Presence of Surfactants. Chemical Papers. 2014;68(1):65-73.

16. Dias JM, Alvim-Ferraz MC, Almeida MF, et al. Waste Materials for Activated Carbon Preparation and Its Use in Aqueous-Phase Treatment: A Review. J Environ Manage. 2007;85(4):833-846.

17. Crini G. Non-Conventional Low-Cost Adsorbents for Dye Removal: A Review. Bioresour Technol. 2006;97(9):1061-1085.

18. Doulati Ardejani F, Badii KH, Limaee NY, et al. Adsorption of Direct Red 80 Dye from Aqueous Solution onto Almond Shells: Effect of $\mathrm{pH}$, Initial Concentration and Shell Type. J Hazard Mater. 2008;151(2-3):730-737.

19. Shakoor S, Nasar A. Removal of Methylene Blue Dye from Artificially Contaminated Water Using Citrus Limetta Peel Waste as a Very Low Cost Adsorbent. Journal of the Taiwan Institute of Chemical Engineers. 2016;66:154-163.

20. Zhou Q, Gong W, Xie C, et al. Removal of Neutral Red from Aqueous Solution by Adsorption on Spent Cottonseed Hull Substrate. J Hazard Mater. 2011;185(1):502-506.

21. Shakoor S, Nasar A. Adsorptive Treatment of Hazardous Methylene Blue Dye from Artificially Contaminated Water Using Cucumis Sativus Peel Waste as a Low-Cost Adsorbent. Groundwater for Sustainable Development. 2017;5:152-159.

22. Chowdhury S, Chakraborty S, Saha P Das. Removal of Crystal Violet from Aqueous Solution by Adsorption onto Eggshells: Equilibrium, Kinetics, Thermodynamics and Artificial Neural Network Modeling. Waste and Biomass Valorization. 2013;4(3):655-664.

23. Morais LC, Freitas OM, Gonçalves EP, et al. Reactive Dyes Removal from Wastewaters by Adsorption on Eucalyptus Bark: Variables That Define the Process. Water Research. 1999;33(4):979-988.

24. Garg VK, Moirangthem Amita, Rakesh Kumar, et al. Basic Dye (Methylene Blue) Removal from Simulated Wastewater by Adsorption Using Indian Rosewood Sawdust: A Timber Industry Waste. Dyes and Pigments. 2004;63(3):243-250.

25. Bhattacharyya KG, Arunima Sarma. Adsorption Characteristics of the Dye, Brilliant Green, on Neem Leaf Powder. Dyes and Pigments. 2003;57(3):211-222.

26. Dávila-Jiménez MM, Elizalde-González MP, Hernández-Montoya V. Performance of Mango Seed Adsorbents in the Adsorption of Anthraquinone and Azo Acid Dyes in Single and Binary Aqueous Solutions. Bioresour Technol. 2009;100(24):6199-6206. 
27. Hai TN. Comments on "Effect of Temperature on the Adsorption of Methylene Blue Dye onto Sulfuric Acid-Treated Orange Peel". Chemical Engineering Communications. 2017;204(1):134-139.

28. Do Nascimento GE, Duarte MM, Campos NF, et al. Adsorption of Azo Dyes Using Peanut Hull and Orange Peel: A Comparative Study. Environ Technol. 2014;35(9-12):1436-1453.

29. Lam SS, Liew RK, Wong YM, et al. Microwave-Assisted Pyrolysis with Chemical Activation, an Innovative Method to Convert Orange Peel into Activated Carbon with Improved Properties as Dye Adsorbent. Journal of Cleaner Production. 2017;162:1376-1387.

30. Fang J, Gao B, Zimmerman AR, et al. Physically $\left(\mathrm{CO}_{2}\right)$ Activated Hydrochars from Hickory and Peanut Hull: Preparation, Characterization, and Sorption of Methylene Blue, Lead, Copper, and Cadmium. RSC Advances. 2016;6(30):24906-24911.

31. Argun ME, Güclü D, Karatas M. Adsorption of Reactive Blue 114 Dye by Using a New Adsorbent: Pomelo Peel. Journal of Industrial and Engineering Chemistry. 2014;20(3):1079-1084.

32. Hameed BH, Mahmoud DK, Ahmad AL. Sorption of Basic Dye from Aqueous Solution by Pomelo (Citrus grandis) Peel in a Batch System. Colloids and Surfaces A: Physicochemical and Engineering Aspects. 2008;316(1-3):78-84

33. Ponnusami V, Vikram S, Srivastava SN. Guava (Psidium guajava) Leaf Powder: Novel Adsorbent for Removal of Methylene Blue from Aqueous Solutions. Journal of Hazardous Materials. 2008;152(1):276-286.

34. Liang J, Wu J, Li P, et al. Shaddock Peel as a Novel Low-Cost Adsorbent for Removal of Methylene Blue from Dye Wastewater. Desalination and Water Treatment. 2012;39(1-3):70-75.

35. Shakoor S, Nasar A. Adsorptive Decontamination of Synthetic Wastewater Containing Crystal Violet Dye by Employing Terminalia Arjuna Sawdust Waste. Groundwater for Sustainable Development. 2018;7:30-38.

36. Mashkoor F, Nasar A, Inamuddin, et al. Exploring the Reusability of Synthetically Contaminated Wastewater Containing Crystal Violet Dye Using Tectona Grandis Sawdust as a Very Low-Cost Adsorbent. Scientific Reports. 2018;8(1):8314.

37. Sulak MT, Demirbas E, Kobya M. Removal of Astrazon Yellow 7GL from Aqueous Solutions by Adsorption onto Wheat Bran. Bioresour Technol. 2007;98(13):2590-2598.

38. Malekbala MR, Hosseini S, Kazemi Yazdi S, et al. The Study of the Potential Capability of Sugar Beet Pulp on the Removal Efficiency of Two Cationic Dyes. Chemical Engineering Research and Design. 2012;90(5):704-712.

39. Langmuir I. The Constitution and Fundamental Properties of Solids and Liquids. Part I. Solids. Journal of the American Chemical Society. 1916;38(11):2221-2295.
40. Nasar A. Polyaniline (PANI) Based Composites for the Adsorptive Treatment of Polluted Water. In: Nasar A, editor. Smart Polymers and Composites. Materials Research Forum LLC; 2018. p. 41-64.

41. Freundlich HMF. Over the Adsorption in Solution. J Phys Chem. $1906 ; 57: 385-470$

42. Temkin M, Pyzhev V. Kinetics of Ammonia Synthesis on Promoted Iron Catalysts. Acta Phys Chim USSR. 1940;12:327-356.

43. Lagergren SY. Zur Theorie Der Sogenannten Adsorption Gelöster Stoffe. Handlingar: Kungliga Svenska Vetenskapsakad. 1898;24(4):1-39.

44. Qin Q, Ma J, Liu K. Adsorption of Anionic Dyes on AmmoniumFunctionalized MCM-41. Journal of Hazardous Materials. 2009;162(1):133-139.

45. Ho YS, McKay G. Sorption of Dye from Aqueous Solution by Peat Chemical Engineering Journal. 1998;70(2):115-124

46. Chen L, Bai B. Equilibrium, Kinetic, Thermodynamic, and in Situ Regeneration Studies about Methylene Blue Adsorption by the Raspberrylike TiO @yeast Microspheres. Industrial and Engineering Chemistry Research. 2013;52:15568-15577.

47. Low MJD. Kinetics of Chemisorption of Gases on Solids. Chemical Reviews. 1960;60(3):267-312.

48. Kyzas GZ, Lazaridis NK, Mitropoulos AC. Removal of Dyes from Aqueous Solutions with Untreated Coffee Residues as Potential LowCost Adsorbents: Equilibrium, Reuse and Thermodynamic Approach. Chemical Engineering Journal. 2012;(189-190):148-159.

49. Mane VS, Babu PVV. Studies on the Adsorption of Brilliant Green Dye from Aqueous Solution onto Low-Cost $\mathrm{NaOH}$ Treated Saw Dust. Desalination. 2011;273(2-3):321-329.

50. Bulut Y, Aydin H. A Kinetics and Thermodynamics Study of Methylene Blue Adsorption on Wheat Shells. Desalination. 2006;194(1-3):259-267.

51. Pavan FA, Mazzocato AC, Gushikem Y. Removal of Methylene Blue Dye from Aqueous Solutions by Adsorption Using Yellow Passion Fruit Peel as Adsorbent. Bioresource Technology. 2008;99(8):3162-3165.

52. Abdel-Ghani NT, Hefny M, El-Chaghaby GAF. Removal of Lead from Aqueous Solution Using Low Cost Abundantly Available Adsorbents. Int J Environ Sci Tech. 2007;4(1):67-73.

53. Ozdes D, Duran C, Senturk HB, et al. Kinetics, Thermodynamics, and Equilibrium Evaluation of Adsorptive Removal of Methylene Blue onto Natural Illitic Clay Mineral. Desalination and Water Treatment. 2014;52(1-3):208-218.

54. Kong L, Gong L, Wang J. Removal of Methylene Blue from Wastewater Using Fallen Leaves as an Adsorbent. Desalination and Water Treatment. 2015;53(9):2489-2500. 